\title{
Aligning One-Dimensional DNA Duplexes into Two-Dimensional Crystals
}

Chuan Zhang, Yu He, Yi Chen, Alexander E. Ribbe, and Chengde Mao*

Department of Chemistry, Purdue University, 560 Oval Drive, West Lafayette, Indiana 47907, USA

\section{Supporting Information}

\section{Experimental Methods}

Oligonucleotides. DNA oligonucleotides were designed by a computer program "SEQUIN" (N. C. Seeman, J. Biomol. Struct. Dyn. 1990, 8, 573-581.), purchased from Integrated DNA Technologies, Inc., and purified by $20 \%$ denaturing polyacrylamide gel electrophoresis (PAGE).

Self-assembly of DNA 2D crytals. $20 \mu \mathrm{L}$ of $1-100 \mu \mathrm{M}$ DNA in Tris-Acetic-EDTA/ $\mathrm{Mg}^{2+}$ buffer (TAE/ $\mathrm{Mg}^{2+}$ buffer) was slowly cooled from $95^{\circ} \mathrm{C}$ to $25^{\circ} \mathrm{C}$ over 72 hours. The TAE/ $\mathrm{Mg}^{2+}$ buffer consisted of Tris base (40 mM, pH 8.0), acetic acid (20 mM), EDTA (2 mM), and $\mathrm{Mg}(\mathrm{Ac})_{2}(12.5$ $\mathrm{mM})$.

Thermal Denaturation Experiment. After DNA self-assembly, the DNA solution $(2 \mu \mathrm{M})$ was transferred to a quartz cuvette, and TAE/ $\mathrm{Mg}^{2+}$ buffer was used as a blank. Thermal denaturation was monitored at $260 \mathrm{~nm}$ on a Varian Cary 100 Bio UV/Visible Spectrophotometer, temperature increase or decrease rate was set for $0.1^{\circ} \mathrm{C} \mathrm{min}^{-1}$.

AFM imaging: A drop of DNA sample solution $(5 \mu \mathrm{L})$ was spotted onto a freshly cleaved mica surface (Ted Pella, Inc.) and left to adsorb to the surface for $30 \mathrm{~s}$, then TAE/ $\mathrm{Mg}^{2+}$ buffer $(50 \mu \mathrm{L})$ was placed onto the mica. Imaging was performed by tapping-mode AFM under TAE $/ \mathrm{Mg}^{2+}$ in a fluid cell on a Multimode NanoScope IIIa, using NP-S tips (Veeco Inc.). Alternatively, after DNA adsorbed onto mica surface, $30 \mu \mathrm{L} 2 \mathrm{mM} \mathrm{Mg}(\mathrm{Ac})_{2}$ solution was added on top of the DNA sample and quickly blew away by compressed air. Then the samples were imaged in air.

Fluorescence imaging. $2 \mu \mathrm{L}$ of DNA solution (in $\mathrm{TAE} / \mathrm{Mg}^{2+}$ buffer) was spotted onto clean glass slide, and sat there for 15 min to allow DNA arrays to absorb onto glass surface. Then $1 \mu \mathrm{L}$ of YOYO-1 solution (1.7 $\mu \mathrm{M}$ in TAE/ $\mathrm{Mg}^{2+}$ buffer) was spotted onto the DNA sample. The YOYO-1 stained DNA sample was immediately covered with a coverslip and imaged with a fluorescence microscope. The images were taken with an excitation wavelength of $450 \mathrm{~nm}$ and an emission wavelength of $520 \mathrm{~nm}$. 
Figure S1. Thermal denaturation of DNA 2D crystals. The relative change of optical density was monitored at $260 \mathrm{~nm}$. Solid line is for the DNA 2D crystals. The dotted line is for a control DNA, which is 20 bases long (sequence: 5' - ACTGGCCAGT GGTTCGAACC - 3'). It contains the two central 10-base-long central segments but lack the two outside 6-base-long segments. Note that the control DNA shows only one sharp transition that corresponds to the long duplex formation. The DNA 2D crystals have two transitions: one sharp transition at higher temperature corresponding to the duplex formation; the other broad transition at lower temperature corresponding to the hybridization of the outside 6-base-long segments.

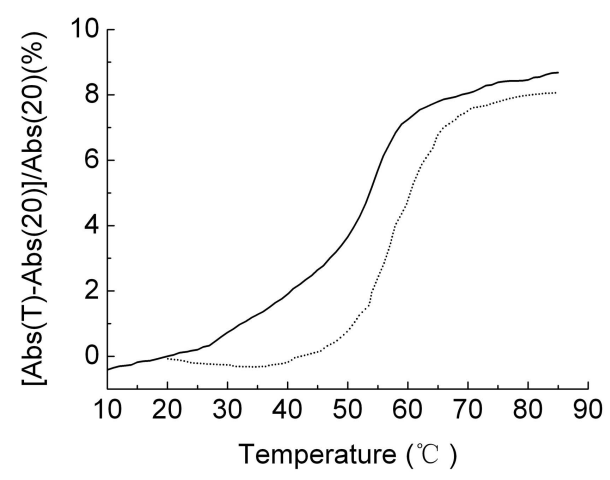

Figure S2. 2\% Agarose gel electrophoretic analysis of the self-assembly of the 20-baselong control DNA strand. The length of the assembled duplexes has a wide distribution and center at $\sim 600$ basepairs (bp), corresponding to a DNA duplex containing 60 component strands.

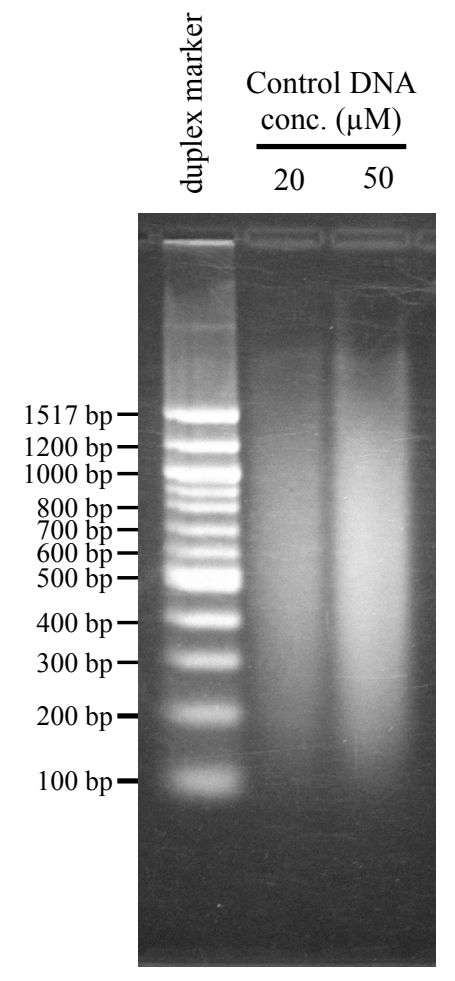


Figure S3. AFM images of DNA samples assembled at different DNA concentrations. At each DNA concentration, a pair of images with different scanning sizes is shown.
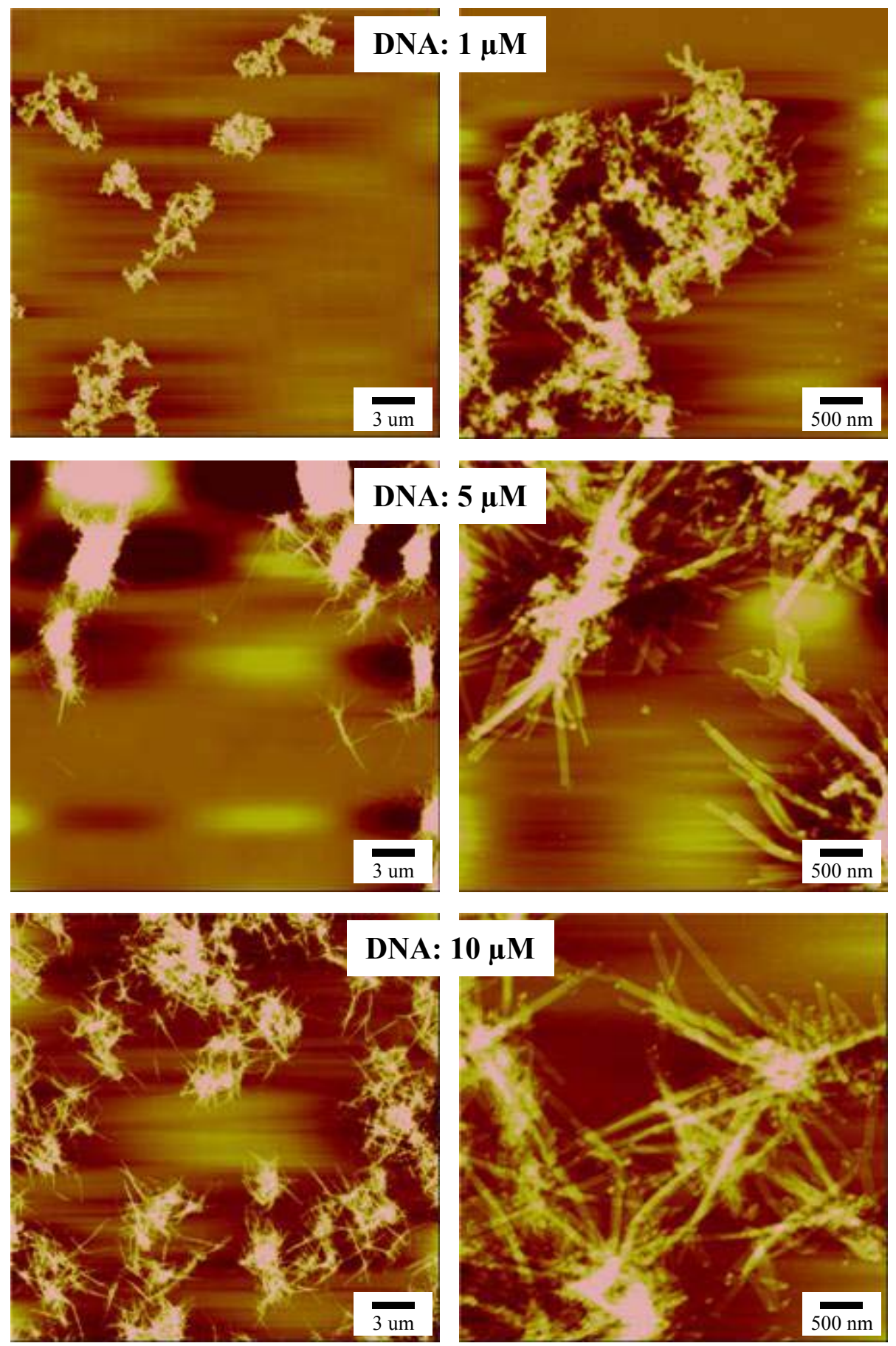

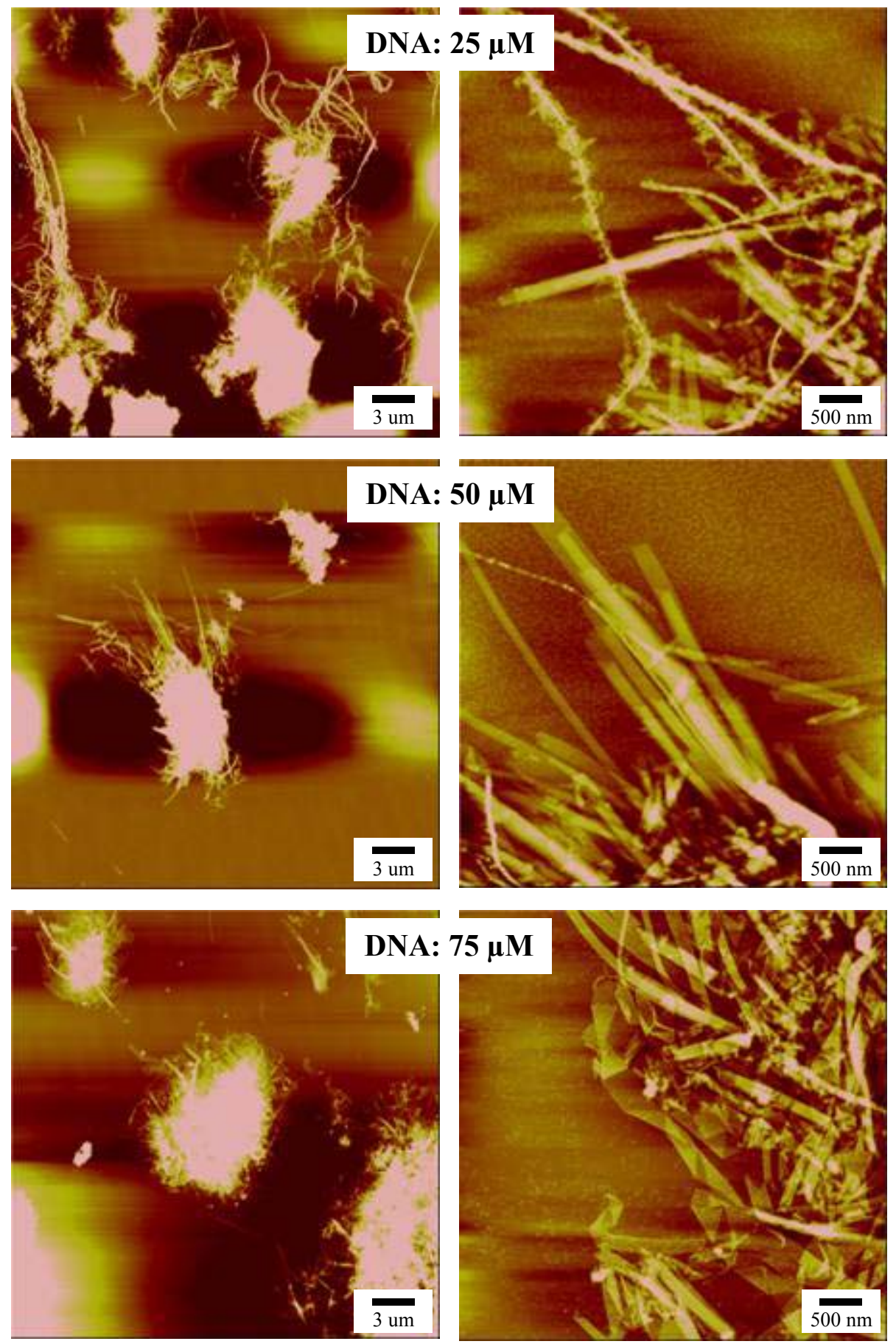

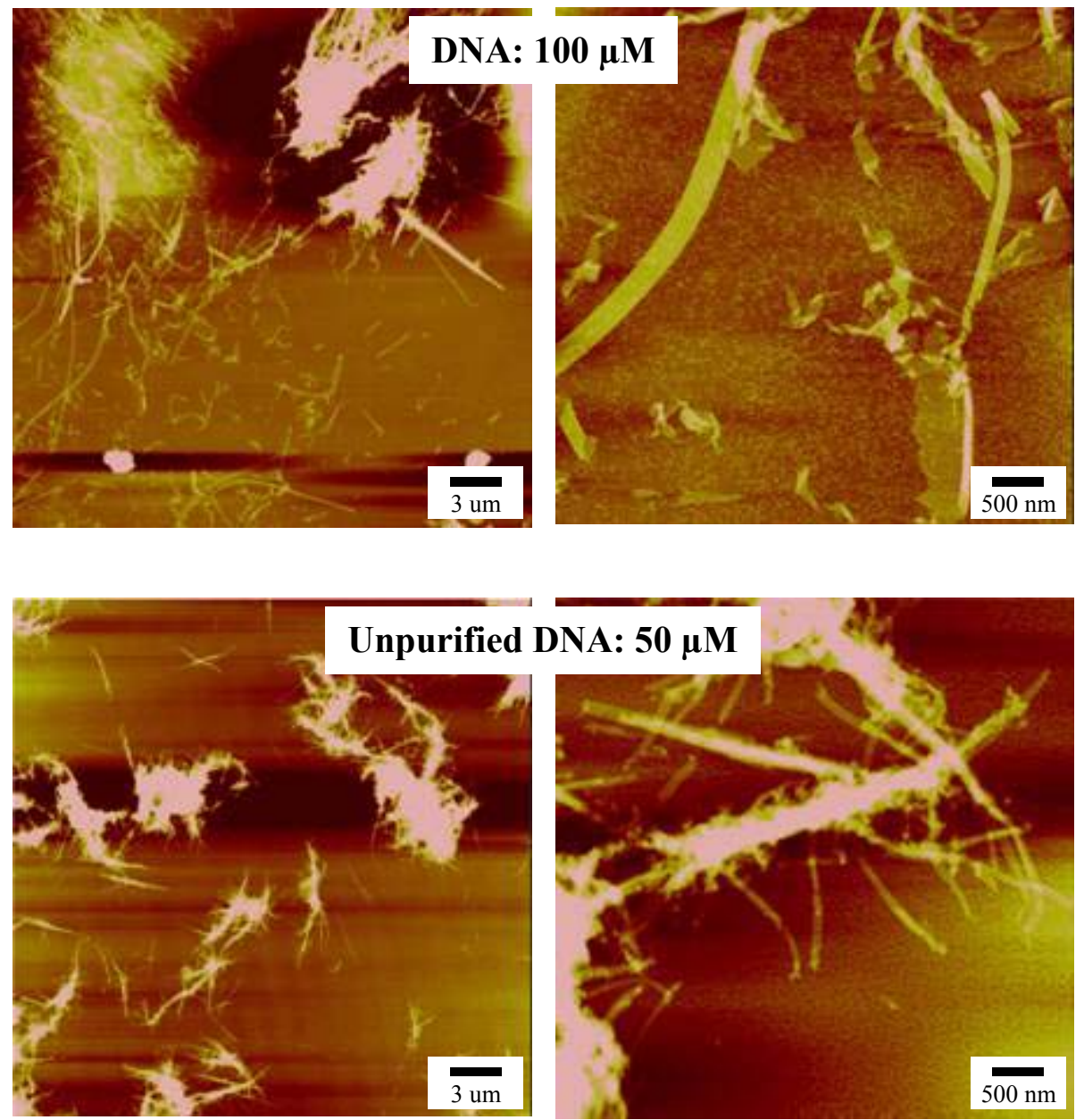

Figure S4. Fluorescence microscopy images of DNA samples assembled at $100 \mu \mathrm{M}$. (a) Aggregates of DNA nanotubes and (b) dispersed DNA nanotubes.

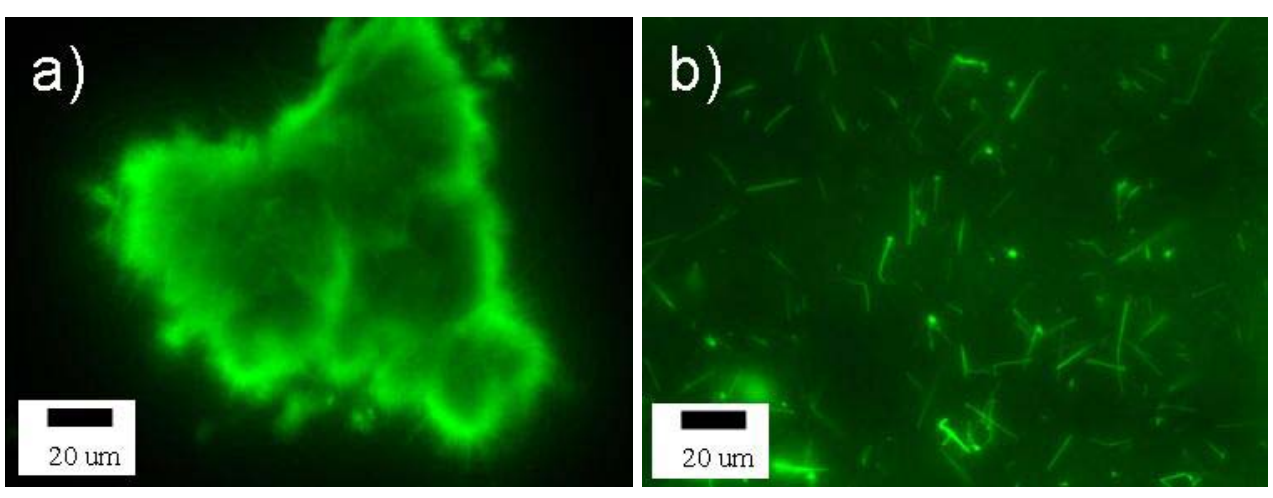

